\title{
Automating Quality Measures for Heart Failure Using Natural Language Processing: A Descriptive Study in the Department of Veterans Affairs
}

Jennifer Hornung Garvin ${ }^{1,2,3,4,5}$, MBA, PhD; Youngjun Kim ${ }^{2,6}$, MS; Glenn Temple Gobbel ${ }^{7,8}, \mathrm{PhD}$, DVM; Michael E Matheny $^{7,8}$, MPH, MD, MS; Andrew Redd ${ }^{2,4}$, PhD; Bruce E Bray ${ }^{2,3}$, MD; Paul Heidenreich ${ }^{9}$, MD, MS; Dan Bolton ${ }^{2,4}$, $\mathrm{PhD}$; Julia Heavirland ${ }^{2}$, MA; Natalie Kelly ${ }^{2}$, MBA; Ruth Reeves ${ }^{7,8}$, PhD; Megha Kalsy ${ }^{2,3}$, PhD; Mary Kane Goldstein $^{10,11}$, MD, MS; Stephane M Meystre ${ }^{2,6}, \mathrm{MD}, \mathrm{PhD}$

\footnotetext{
${ }^{1}$ Health Information Management and Systems Division, School of Health and Rehabilitation Sciences, The Ohio State University, Columbus, OH, United States

${ }^{2}$ IDEAS 2.0 Health Services Research and Development Research Center, Salt Lake City Veterans Affairs Healthcare System, Department of Veterans Affairs, Salt Lake City, UT, United States

${ }^{3}$ Department of Biomedical Informatics, School of Medicine, University of Utah, Salt Lake City, UT, United States

${ }^{4}$ Division of Epidemiology, Department of Medicine, University of Utah, Salt Lake City, UT, United States

${ }^{5}$ Geriatric Research, Education and Clinical Center, Salt Lake City Veterans Affairs Healthcare System, Department of Veterans Affairs, Salt Lake City, UT, United States

${ }^{6}$ Translational Biomedical Informatics Center, Medical University of South Carolina, Charleston, SC, United States

${ }^{7}$ Geriatric Research, Education and Clinical Center, Tennessee Valley Healthcare System, Department of Veterans Affairs, Nashville, TN, United States

${ }^{8}$ Department of Biomedical Informatics, School of Medicine, Vanderbilt University, Nashville, TN, United States

${ }^{9}$ Palo Alto Geriatric Research, Education and Clinical Center, Veterans Affairs Palo Alto Health Care System, Department of Veterans Affairs, Stanford University, Palo Alto, CA, United States

${ }^{10}$ Medical Service, Veterans Affairs Palo Alto Health Care System, Palo Alto, CA, United States

${ }^{11}$ Department of Medicine, Stanford University School of Medicine, Stanford, CA, United States
}

\section{Corresponding Author:}

Jennifer Hornung Garvin, MBA, PhD

Health Information Management and Systems Division

School of Health and Rehabilitation Sciences

The Ohio State University

453 W 10th Ave

Columbus, OH, 43210

United States

Phone: 12156203390

Email: jennifer.garvin@hsc.utah.edu

\section{Abstract}

Background: We developed an accurate, stakeholder-informed, automated, natural language processing (NLP) system to measure the quality of heart failure (HF) inpatient care, and explored the potential for adoption of this system within an integrated health care system.

Objective: To accurately automate a United States Department of Veterans Affairs (VA) quality measure for inpatients with HF.

Methods: We automated the HF quality measure Congestive Heart Failure Inpatient Measure 19 (CHI19) that identifies whether a given patient has left ventricular ejection fraction (LVEF) $<40 \%$, and if so, whether an angiotensin-converting enzyme inhibitor or angiotensin-receptor blocker was prescribed at discharge if there were no contraindications. We used documents from 1083 unique inpatients from eight VA medical centers to develop a reference standard $(\mathrm{RS})$ to train $(\mathrm{n}=314)$ and test $(\mathrm{n}=769)$ the Congestive Heart Failure Information Extraction Framework (CHIEF). We also conducted semi-structured interviews (n=15) for stakeholder feedback on implementation of the CHIEF. 
Results: The CHIEF classified each hospitalization in the test set with a sensitivity (SN) of 98.9\% and positive predictive value of $98.7 \%$, compared with an RS and SN of $98.5 \%$ for available External Peer Review Program assessments. Of the 1083 patients available for the NLP system, the CHIEF evaluated and classified $100 \%$ of cases. Stakeholders identified potential implementation facilitators and clinical uses of the CHIEF.

Conclusions: The CHIEF provided complete data for all patients in the cohort and could potentially improve the efficiency, timeliness, and utility of HF quality measurements.

(JMIR Med Inform 2018;6(1):e5) doi: 10.2196/medinform.9150

\section{KEYWORDS}

natural language processing (NLP); heart failure; left ventricular ejection fraction (EF); informatics; quality measures

\section{Introduction}

Heart failure (HF) is associated with substantial morbidity, mortality, and consumption of medical resources. HF affects approximately five million Americans and is the number one reason for discharge for Veterans treated within the United States Department of Veterans Affairs (VA) health care system $[1,2]$. The cost of HF care is high, and will remain a significant concern for the US health care system with high mortality; $50 \%$ of Medicare beneficiaries do not survive three years after an HF hospitalization $[3,4]$.

The cost of treating HF in the United States is estimated to increase from US $\$ 31$ billion in 2012 to US $\$ 70$ billion by 2030 [5-7]. Despite decreased HF hospitalizations between 2001 and 2009, the presence of HF as a secondary condition in hospitalizations increased over the same period [7], with research suggesting that $55 \%$ of acute exacerbations were preventable [8]. HF was the fourth most common diagnosis for hospitalization in 2014 [9] and prevalence figures indicate that 6.6 million American adults 18 years of age or older (2.8\%) have HF [10]. It is estimated that an additional 3 million adults (25\% increase) will be diagnosed with HF by 2030 [3,5], and it is important to implement evidence-based, guideline-concordant care that can improve HF symptoms, prolong life, and reduce readmissions [3,6,11-15].

The VA HF quality measure known as Congestive Heart Failure Inpatient Measure 19 (CHI19) describes how often guideline-concordant medical therapy, in the form of angiotensin-converting enzyme inhibitor (ACEI) or angiotensin-receptor blocker (ARB) use, is provided for patients with left ventricular ejection fraction (LVEF) of $<40 \%$ at the time of discharge, unless there are contraindications. The same information is currently collected for outpatients using the Congestive Heart Failure Outpatient Measure 7 (CHF7): HF-Outpatient Left Ventricular Failure (LVF) documented and Congestive Heart Failure Outpatient Measure 14 (CHF14): HF-Outpatient LVEF Less Than 40 on ACEI or ARB measures. The measurement of this information is used for accountability within the VA. The use of these measures provides key feedback to patients (through public reporting), providers, and local or regional areas, including the VA's Veterans Integrated Service Networks [16,17]. The measures used by the VA are in alignment with Medicare and are reported publicly [18].

Our primary goal was to develop an efficient and accurate method of obtaining quality data by automating the CHI19 measure, as it is an accountability measure that has been widely used in the VA for many years, and currently requires time-consuming chart abstraction to determine through the External Peer Review Program (EPRP). EPRP provides peer review for the VA through an external medical professional association that abstracts the charts manually to populate a dashboard [19]. Additional HF measures abstracted by EPRP include Congestive Heart Failure Inpatient Measure 10 (CHI10) and Congestive Heart Failure Inpatient Measure 20 (CHI20). CHI10 refers to HF patients who were assessed for LVF at discharge or patients for whom such an assessment was planned, whereas CHI20 refers to patients who had LVEF <40\% and were taking an ACEI or ARB before being admitted as inpatients.

Using automated methods to share data and measure quality for provider feedback and public reporting is a key goal of the incentives provided by the Centers for Medicare and Medicaid Services, so that certified electronic health records (EHRs) of "meaningful use" criteria can be attained [20]. Some quality measures that use only structured data from the EHR are relatively easy to automate. A challenge for automating the computation of $\mathrm{CHI} 10, \mathrm{CHI} 19$, and CHI20 is that, unlike quality measures that use only structured data [21], these measures require data regarding LVEF and contraindications to medications, which in the VA are primarily in free-text health record documents and are therefore more difficult to extract.

Prior research in informatics in VA showed that health information technology and the use of explicit conceptual models can not only contribute to increasing well-formed and well-grounded health informatics research [22], but can also facilitate evidence-based practice [23] through usability testing, good research design, and implementation methodology [24]. Importantly, prior research indicates that end-user considerations, including where and when the technology is required as well as stakeholder needs and goals, must be identified for successful implementation [25-30]. To this end, we initiated development of an automated natural language processing (NLP) system capable of efficient data capture that could meet end-user needs and generate data for other informatics applications, such that the system would be positioned for adoption and implementation by the VA or other health care organizations. 


\section{Methods}

\section{Setting and Context}

For the system's clinical basis, we used the American Heart Association/American College of Cardiology level 1A clinical evidence, which recommends assessing the left ventricular systolic function and use of ACEI or ARB if the ejection fraction $(\mathrm{EF})$ is $<40 \%$, if there are no contraindications [6,31]. We used the VA Informatics and Computing Infrastructure [32] for NLP development and analysis of EHR patient data from the VA's Corporate Data Warehouse (CDW) [33].

\section{Patient Cohort Identification and Document and Structured Data Acquisition}

We obtained a listing of EPRP abstracted cases involving HF patients discharged from eight VA medical centers. To approximate the general VA patient population, we selected facilities which in total were representative of the VA population in terms of race, ethnicity, and rurality in the fiscal year 2008 to serve as our study cohort. The patient cohort was randomized and split into training and test sets based on the sampling strategy described below. We obtained the associated text integration utilities (TIUs) notes for each patient. The TIUs software processes free-text clinical notes so they can be saved in the Veterans Health Information Systems and Technology Architecture files. We also obtained structured data from the Pharmacy Benefit Management (PBM) software to determine each patient's medications, and International Classification of Diseases, $9^{\text {th }}$ Revision, Clinical Modification (ICD-9-CM) codes, and laboratory data to identify reasons the patient was not prescribed medications (reasons no medications; RNM) for each patient in the cohort. Acquiring these data allowed for comparison of the concepts found in free text through NLP with VA structured data for determination of each patient's medications or RNM.

\section{Sampling Strategy for Natural Language Processing Development}

We used a power analysis that accounted for differences in the prevalence of clinical concepts within notes across the medical centers. We selected the sample size that involved the largest number of patients to determine the test set, in order to accommodate the rarest event (contraindications to ACEIs and ARBs) which was estimated to be $14.9 \%$ based on the HF literature [34]. We determined a sample size of 769 patients for the test set for system performance evaluation, and the remaining patients in the EPRP abstraction set $(n=314)$ served as a separate set for training the NLP system.

\section{Reference Standard Development for Natural Language Processing Development}

We used Knowtator Protégé plug-in software [35] to annotate the training and evaluation (test) sets, to create a Reference Standard (RS) to undertake an accurate performance evaluation [36] of the NLP system at both the concept (eg, EF, medications,
RNM) and patient (eg, overall determination or classification of a patient meeting the equivalent of CHI19) levels. We developed annotation guidelines that provided explicit examples of concepts (data) to be identified, which documents were preferred for each concept (eg, most recent echocardiogram for $\mathrm{EF}$, and discharge medication reconciliation form for ACEIs and ARBs), annotation at the document level, and how to use the document-level annotations to determine the patient classification with resulting patient-level annotation [37]. We annotated $100 \%$ of the unique patients in our cohort for NLP training and testing. Two annotators independently reviewed the text documents. We measured percent agreement between the annotators across all concepts. The patient- and document-level annotations, as well as differences between concept-level annotations, were resolved via consensus determination by the two annotators with assistance from a subject matter expert (SME) cardiologist who was part of the study team. The annotators were required to achieve $90 \%$ interannotator agreement (IAA) at the concept level, and were assessed for accuracy before annotating the RS. A cardiologist (SME) reviewed and adjudicated differences when needed. We created the final RS after all differences were resolved. All cases were successfully classified by the annotators with cardiology oversight.

We used two software tools to assist annotators by preannotating concepts for subsequent verification. The first software tool, based on the Apache Unstructured Information Management Architecture (UIMA) framework [38,39], was designated Capture with UIMA of Needed Data using Regular Expressions for Ejection Fraction [40] and used to preannotate EF information. The second tool, the Extensible Human Oracle Suite of Tools [41], was used to preannotate ACEI/ARB medications. Preannotated concepts were read into the Knowtator software for annotators to review and finalize. Annotators reviewed preannotations as well as all other information in the document, based on the annotation guidelines.

\section{Natural Language Processing System Development for Information Extraction}

We based target concepts for NLP development on clinical guidelines, VA policy, and what was currently collected manually through the EPRP process [6,31]. These target concepts also served as elements in an algorithm for calculating VA CHI19 at the time of discharge. We developed an application called the Congestive Heart Failure Information Extraction Framework (CHIEF) [42-44], based on the Apache UIMA framework, to provide robustness and scalability [38]. As depicted in Figure 1, the CHIEF includes modules for (1) clinical text preprocessing (eg, detecting sentences and tokens as well as conducting syntactic analyses), (2) extracting mentions of EF as well as quantitative values, and (3) extracting mentions of medications (eg, ACEIs and ARBs). RNM were extracted with another NLP application called RapTAT [45], and the resulting data were integrated into the CHIEF. 
Figure 1. Congestive heart failure information extraction framework (CHIEF).

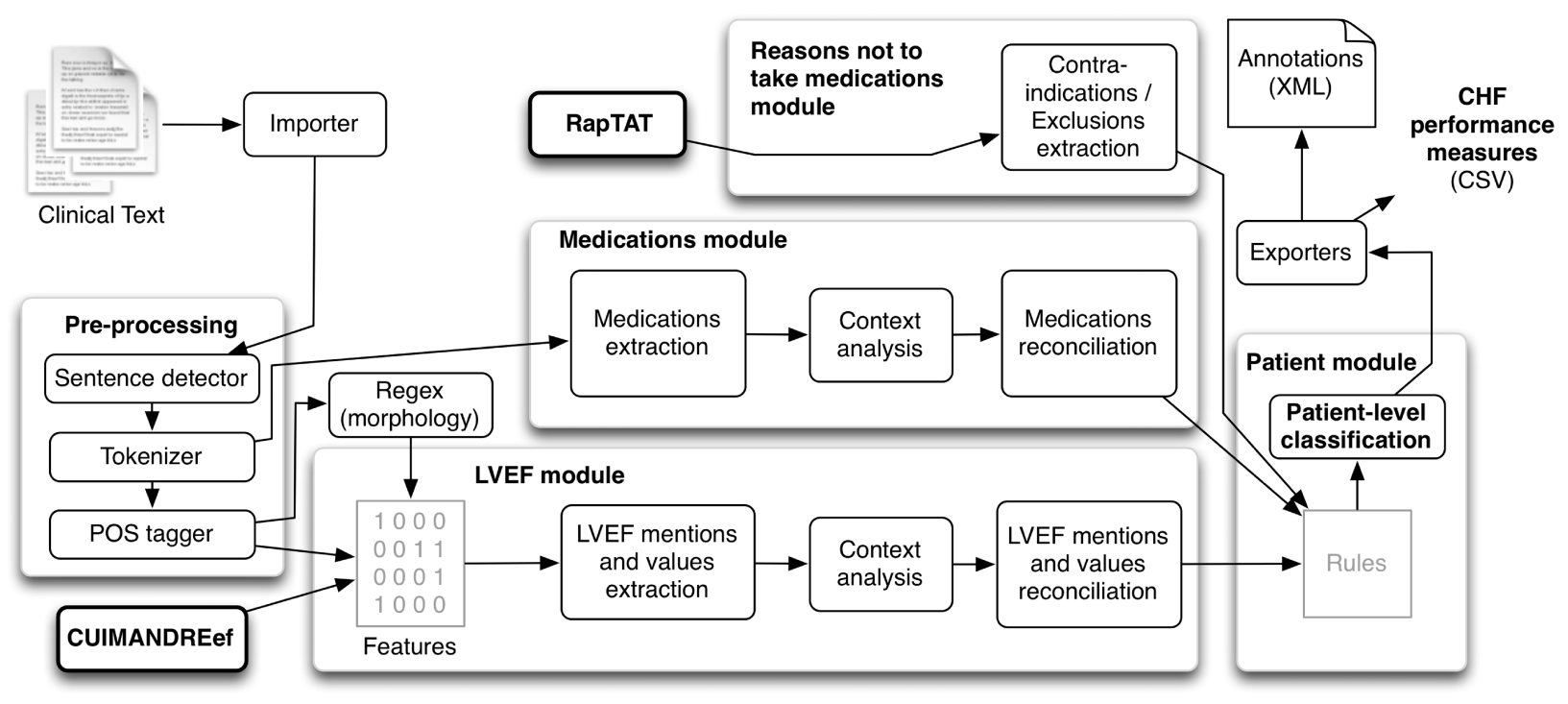

Figure 2. Algorithm to classify the patient as meeting the measure.

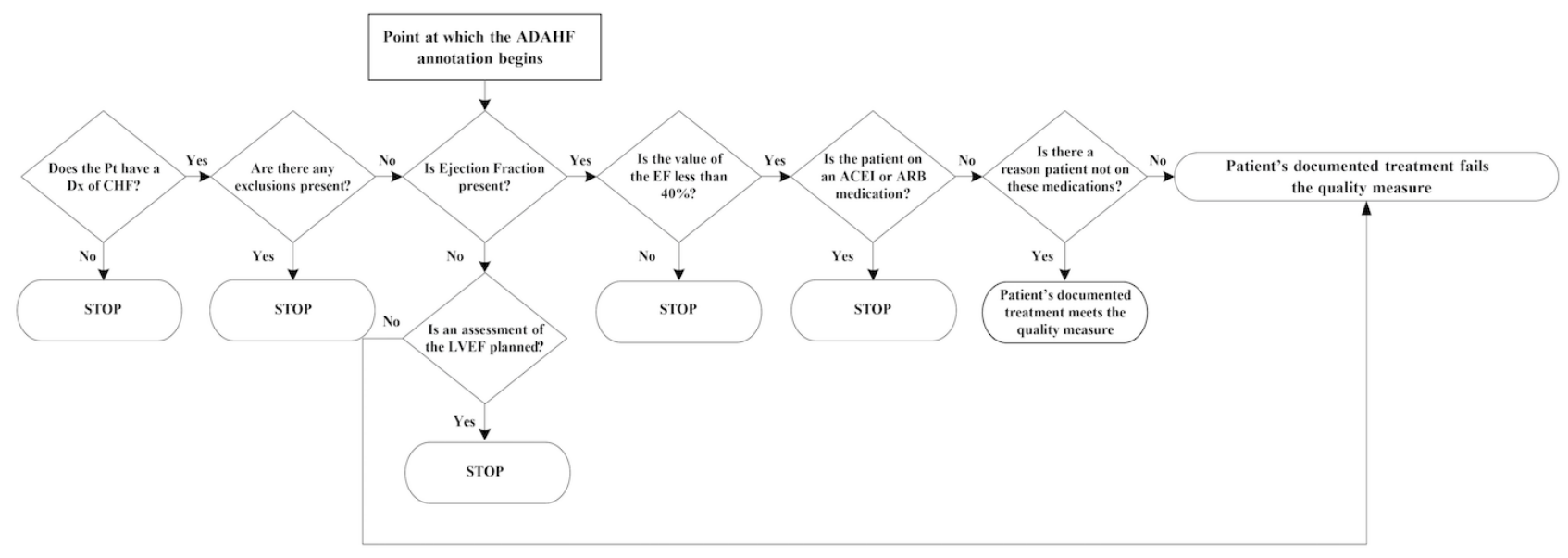

Finally, all extracted information at the concept and patient levels was compared and combined using a set of rules to classify HF treatment performance measures automatically for each patient (see Figure 2). For example, the NLP system assessed whether the patient had an EF recorded (and if the answer was yes, was it $<40 \%$ ?). If the EF was $<40 \%$, then the system determined if the patient was on an ACEI or ARB. If the patient was not, then the system determined if there were RNM. The patient met the measure: if the EF was present but not $<40 \%$; if the EF was $<40 \%$ and there was an active prescription for an ACEI or ARB; or if the patient had an EF $<40 \%$, was not on an ACEI or ARB, and had RNM (see Figure $2)$.

\section{Key Informant and Subject Matter Expert Interviews}

To inform the design of our automated system and to facilitate adoption, we interviewed both key informants and SMEs. We conducted 15 interviews consisting of four key informants and a convenience sample of 11 additional SMEs. The four key informants that were interviewed were VA quality measurement experts with national roles and VA-wide knowledge about inpatient HF quality measurements and the use of quality measurements for HF in the VA. Based on a snowball sampling design, the key informants recommended the inclusion of 11 additional VA-based SMEs. We recruited and interviewed these SMEs, who were responsible for receiving and interpreting quality monitoring data, and included VA cardiologists and HF quality experts with extensive experience in making decisions regarding the quality measures to be used and presentation of the results of quality assessments. The key informants' and SMEs' experience in the VA ranged from 2 to 35 years, and from 2 to 33 years in quality management.

To develop our interview questions, we drew upon the Promoting Action on Research Implementation in Health Sciences (PARiHS) framework [46,47], which postulates that evidence, context, and facilitation are central to implementation. We complemented the PARiHS framework with the Socio-Technical Model of Health Information Technology to focus on the information technology context of potential implementation [48]. We studied the potential of integrating an automated quality measurement system in the VA through these 
interviews, and will detail our applied thematic analysis in a future manuscript.

\section{Measurements}

We compared the CHIEF system output to the human annotator-created RS to compute performance at the concept level and for the patient-level binary classification of meeting or not meeting the CHI19 measure. We calculated sensitivity $(\mathrm{SN})$, specificity (SP), and positive predictive value (PPV) in addition to the F-measure, which is the harmonic mean of the SN and PPV [49]. We also computed the SN of the NLP test set based on the results of the EPRP review at the patient level for target concepts, and the overall binary classification of meeting the CHI19 measure. We computed Cohen's kappa [50] parameter to determine concordance between the structured prescription data from the PBM package to determine patient medications, and both the human-annotated RS and the NLP output. Similarly, we compared ICD-9-CM codes and laboratory results to both the human-annotated RS and the NLP output to find RNM. We then summarized the interview findings to complement the system development.

\section{Institutional Review Board Approval}

This study was approved by the University of Utah and the Tennessee Valley Healthcare System Institutional Review

Figure 3. Data capture strategy.
Boards (IRBs). Informed patient consent was waived for text document use. The IRB approved informed consent with a waiver of documentation of consent for the key informant and SME interviews.

\section{Results}

\section{Documents Obtained for the Research}

We retrieved 45,703 free-text (TIU) documents from 1083 patients (314 in the training set and 769 in the test set). Using a systematic sample (every tenth document), we mapped the document title names to the following documents types in our corpus: history and physical, progress notes, cardiology consult, echocardiogram, pharmacy (medication reconciliation), pharmacy (other), consult (other), discharge summary, nursing note, and other (general). After mapping and during annotation, we found that EF was most commonly found in the assessment and current history sections of any note in which these sections were used (eg, history and physicals, progress notes, cardiology consults). Medications (ACEI/ARB) were most commonly found in the assessment and medication sections, LVEF was most commonly found in the echocardiogram results and assessment sections, and RNM were most commonly found in the assessment section [51]. Please see Figure 3 for the data capture strategy used in the research.

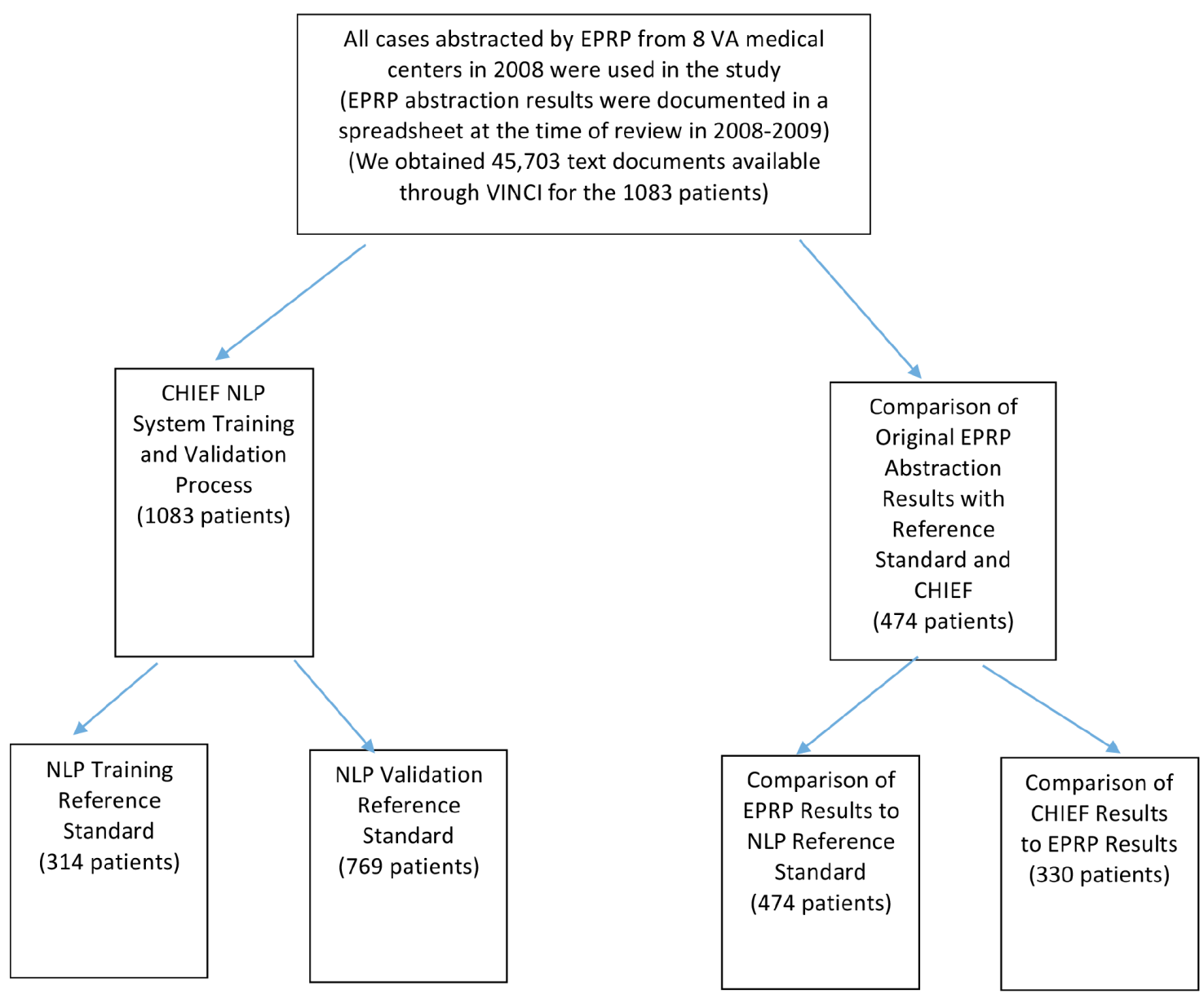




\section{Reference Standard Development}

The IAA was found to be $91 \%$ in a pairwise comparison of all concepts within the documents in the project corpus for the RS [52]. In consultation with the cardiologist as needed, the annotation team was able to agree on this consensus RS for all patient-level classifications.

\section{Performance of the Natural Language Processing System}

We developed the CHIEF NLP system (see Figure 1). When evaluated at the information extraction level, CHIEF extracted relevant mentions and values of LVEF, medications, and RNM with a range of high to fair recall. HF medications were extracted with recall of $97.8-99.7 \%$ and precision of $96-97.8 \%$; mentions of LVEF were extracted with recall of 97.8-98.6\% and precision of 98.6-99.4\%, and RNM were less common and more difficult to extract, only reaching fair accuracy with $31.1-40.4 \%$ recall and $24.7-32.1 \%$ precision [53]. As explained earlier, this extracted information was then combined at the patient level using a set of rules. At the patient level, as shown in Table 1 and compared with the RS, CHIEF achieved almost 99\% F-measure, SN, and PPV for classifying a patient admission as meeting the $\mathrm{CHI} 19$ measure. The SP was $85.5 \%$. The CHIEF could also classify whether the performance measure was met, assess LVEF, and determine whether the EF was below $40 \%$, with F-measures of $98.80 \%, 99.52 \%$, and $95.52 \%$, respectively. However, the system identified more false positives in medication prescriptions (PPV, <90\%; F-measure, 93.53\%). For concept extraction, we used machine learning-based approaches (fully automated) rather than rule-based or just keyword searching, and for classification we used several rules (as depicted in Figure 2). Note that for classification we programmed three sets of rules based on decisions depicted in Figure 2. The full set of rules can be found in Multimedia Appendix 1.

The lowest performance of the NLP system was measured for RNM (ie, ACEIs or ARBs), with an SN of 26.9\%, SP of 99.4\%, and PPV of $90.7 \%$. This performance level was affected by RNM being the least structured, most varied, and least common of all of the concepts evaluated, with only 145 patients in our testing corpus having RNM. When we restricted our analysis to patients with an EF <40\% (according to the RS) who were discharged without prescriptions for ACEIs or ARBs $(n=70)$, performance increased slightly (SN, 33\%; SP, 92.3\%; PPV, 95\%; and F-measure, 49\%). However, when evaluating hospitalizations for which it was critical for the system determination for patient classification $(n=37$; $E F<40 \%$ and discharged without prescriptions according to system output), the RS found more RNM than the NLP system found, but the $\mathrm{SN}$ of the system increased to $78 \%$. The PPV was relatively unchanged at $81.8 \%$, for an F-measure of $80 \%$.

\section{Concordance of Reference Standard and External Peer Review Program Results}

Table 2 provides a comparison of the human-annotated RS and the NLP system output to the EPRP review findings. Of the 1083 patients, only 474 patient abstractions had the equivalent data elements to those we captured with CHIEF and were classified as meeting or not meeting the measure. Only 10 patients were present in the EPRP data who did not meet the CHI19 measure. Based on this finding, the SN is the only relevant metric, and with only 10 patients we could not get a precise estimate of any other metrics.

Table 1. Performance of the Congestive Heart Failure Information Extraction Framework (CHIEF) system for each patient compared to the reference standard established by human review (patient-level classification CHI19).

\begin{tabular}{|c|c|c|c|}
\hline Patient-Level Classification & $\begin{array}{l}\text { Sensitivity Estimate } \\
\%(95 \% \mathrm{CI})\end{array}$ & $\begin{array}{l}\text { Positive Predictive Value Estimate } \\
\%(95 \% \mathrm{CI})\end{array}$ & F-measure \\
\hline Measure $\mathrm{CHI} 19^{\mathrm{a}}$ met & $98.9(97.8,99.5)$ & $98.7(97.6,99.4)$ & 98.8 \\
\hline Left Ventricular Systolic Function assessed & $100.0(99.5,100.0)$ & $99.0(98.0,99.6)$ & 99.5 \\
\hline $\mathrm{EF}^{\mathrm{b}}<40 \%$ & $96.8(94.6,98.3)$ & $95.1(92.6,97.0)$ & 96.0 \\
\hline $\mathrm{ACEI}^{\mathrm{c}}$ or $\mathrm{ARB}^{\mathrm{d}}$ & $99.2(98.1,99.7)$ & $88.5(85.8,90.8)$ & 93.5 \\
\hline Reason not on medications & $26.9(20.0,34.9)$ & $90.7(77.9,97.4)$ & 41.5 \\
\hline
\end{tabular}

${ }^{\mathrm{a}} \mathrm{CHI} 19$ : Congestive Heart Failure Inpatient Measure 19; LVEF >40 on ACEI/ARB at discharge.

${ }^{\mathrm{b}} \mathrm{EF}$ : ejection fraction.

${ }^{\mathrm{c}} \mathrm{ACEI}$ : angiotensin-converting enzyme inhibitor.

${ }^{\mathrm{d}} \mathrm{ARB}$ : angiotensin-receptor blocker.

Table 2. Sensitivity of patient-level classification of the reference standard and Congestive Heart Failure Information Extraction Framework (CHIEF) based on External Peer Review Program (EPRP) review.

\begin{tabular}{llll}
\hline Patient-Level Classification/Sensitivity & $\begin{array}{l}\text { Number of Patients in Agreement with } \\
\text { EPRP Review }\end{array}$ & $\begin{array}{l}\text { Number of Patients with Corresponding } \\
\text { EPRP Review }\end{array}$ & $\begin{array}{l}\text { Sensitivity Estimate } \\
\%(95 \% \text { CI) }\end{array}$ \\
\hline Classification in Reference Standard & 469 & 474 & 98.95 (97.56, 99.66) \\
Classification from CHIEF & 325 & 330 & $98.48(96.50,99.51)$ \\
\hline
\end{tabular}


Table 3. The External Peer Review Program (EPRP) quality measurement designation of patients in the training and test sets.

\begin{tabular}{|c|c|c|c|c|c|}
\hline Measure & Data Present & Measure Met & $\begin{array}{l}\text { Total } \\
\mathrm{n}(\%)\end{array}$ & $\begin{array}{l}\text { Number in Test } \\
\mathrm{n}(\%)\end{array}$ & $\begin{array}{l}\text { Number in Training } \\
\mathrm{n}(\%)\end{array}$ \\
\hline \multirow[t]{3}{*}{ CHI10 ${ }^{\mathrm{a}}$} & No & N/A & $74(6.83)$ & $61(7.93)$ & $13(4.14)$ \\
\hline & Yes & No & $4(0.36)$ & $4(0.13)$ & $0(0.00)$ \\
\hline & & Yes & $1005(92.79)$ & $704(91.54)$ & $301(95.85)$ \\
\hline \multirow[t]{3}{*}{$\mathrm{CHI}^{\mathrm{b}}{ }^{\mathrm{b}}$} & No & N/A & $600(55.40)$ & $433(56.30)$ & $167(53.18)$ \\
\hline & Yes & No & $9(0.83)$ & $6(0.78)$ & $3(0.31)$ \\
\hline & & Yes & $474(43.76)$ & $330(42.91)$ & $144(45.85)$ \\
\hline \multirow[t]{3}{*}{$\mathrm{CHI} 20^{\mathrm{c}}$} & No & N/A & $768(70.91)$ & $546(71.09)$ & $222(28.90)$ \\
\hline & Yes & No & $9(0.83)$ & $6(0.78)$ & $3(0.96)$ \\
\hline & & Yes & $306(28.25)$ & $217(28.22)$ & $89(28.34)$ \\
\hline No data on any measure & & & $54(4.99)$ & $42(5.46)$ & $12(3.82)$ \\
\hline Total sample size & & & $1083(100.00)$ & 769 (100.00) & 314 (100.00) \\
\hline
\end{tabular}

${ }^{\mathrm{a}} \mathrm{CHI10}$ : Congestive Heart Failure Inpatient Measure 10; inpatient left ventricle function assessed at discharge.

${ }^{\mathrm{b}} \mathrm{CHI}$ 19: Congestive Heart Failure Inpatient Measure 19; LVEF >40 on ACEI/ARB at discharge.

${ }^{\mathrm{c}} \mathrm{CHI} 20$ : Congestive Heart Failure Inpatient Measure 20; LVEF $>40$ on ACEI/ARB prior to inpatient admission.

We compared the EPRP data with both our RS developed with SMEs, and with the results of CHIEF. When we compared the RS to the EPRP patient classifications using the EPRP findings as truth for patients meeting CHI19 in applicable cases in both the training and test sets $(n=474)$, we found the $\mathrm{SN}$ of the RS to be $99.0 \%$. We also compared the NLP results for hospitalizations in the NLP test set $(n=330)$ to the hospitalizations for whom the EPRP provided results for CHI19 using the EPRP findings as truth for patients meeting CHI19 in applicable cases, and found an SN of $98.5 \%$ for the CHIEF. Human annotators classified $100 \%$ of cases as meeting or not meeting the measure. However, we found that there were no EPRP results for $\mathrm{CHI} 19$ for $55.4 \%$ of the patients assessed, even though other measures (such as CHI10 or CHI20) might have been completed, making these EPRP results noncomparable to our results. The CHIEF processed and classified $100 \%$ of patients in the test set, with $92.1 \%$ meeting $\mathrm{CHI} 19$. Meeting the measure required that the case was eligible for the performance measure and that the patient data showed that the case satisfied the performance required by CHI19 (see Table 3).

\section{Concordance Between the Reference Standard, Natural Language Processing Output, and Structured Data}

We found that the agreement (based on Cohen's kappa) between the PBM data and the RS for RNM was 0.326, and the agreement between the PBM and the NLP system output was 0.221. Both results were interpreted as fair agreement [54]. We determined that the low kappa result was due to the PBM data not capturing the reasons why ACEI and ARB were not prescribed, as well as the text documents. When we performed the same calculations for laboratory and ICD-9-CM data for RNM, the laboratory data compared with the RS and NLP output provided kappa values of 0.2083 and 0.1373 , respectively. The ICD-9-CM codes indicated only five patients with RNM and showed no agreement with the RS or NLP system output. Similar to the PBM data, clinical text documents are a better data source to capture reasons not to prescribe than laboratory results and ICD-9-CM data. A kappa statistic was calculated as an aggregate measure using the laboratory results and the ICD-9-CM codes as well, but did not differ from the kappa statistic for the laboratory results alone.

\section{Summary Findings from Interviews}

Key informants and SMEs provided valuable insights about the design of the CHIEF system and the related development and validation methods. The development team held regular meetings with key informants one to two times per year to review design decisions, such as the capture of concepts to approximate the data elements of the measure. For example, the quality measure assesses whether the patient had left ventricular systolic function assessed. The design team used the presence of an EF in the record of the patient to mean that left ventricular systolic function was assessed. Similarly, there are multiple mentions of the EF in a given echocardiogram report. The design team worked with SMEs to determine the most clinically relevant mention to use in the classification algorithm, and targeted the mention in the section of the report that is a narrative summary by the reviewing cardiologist to extract. Last, the key informants agreed that the research team could use a limited document set, rather that the entire medical record for a given patient discharge, to extract and classify the patient's documentation as to whether or not the measure was met.

Interview respondents also discussed several areas related to how the automated NLP processes are potentially aligned with organizational goals and clinical needs. Respondents noted three potential benefits: (1) use of an automated quality measurement system could improve the efficiency of data capture and thus provide it more quickly; (2) an automated system that facilitates redeployment of resources to emerging areas is aligned with VA organizational goals and strategies; and (3) an NLP system 
and the resulting data could be used for clinical purposes, in addition to use in quality measurement.

An automated system has the potential to provide consistent data sources for measurement and new data regarding EF to the VA primary care almanac; it could also serve as a data source for primary care teams, VA dashboards, and clinical decision support (CDS). The system could also provide data organized in a summarized, longitudinal manner, and assist cohort and registry development.

The use of an automated quality measurement process for measuring HF quality appears to be aligned with VA organizational goals, could support the current VA culture of measurement and feedback, and provide needed data for accountability. An automated system could also facilitate meaningful use certification, further electronic quality measurement, and assist real-time (rather than retrospective) measurement.

Key informants and SMEs also suggested specific clinical uses for the NLP system and the resulting data, as follows: HF guideline and quality measurement training for providers, automated review and documentation of LVF, identification of patients needing transitional management and palliative care, summarization of clinical findings and treatment to assist clinician decision-making, and identification and contacting of patients with gaps in evidence-based care to aid quality improvement efforts (care coordination).

The interviews provided important information about the automated NLP system and its potential clinical uses. Further research is needed to identify potential technical and organizational barriers to the use of such an NLP system in the $\mathrm{VA}$, as this would help determine the next steps in potential implementation.

\section{Discussion}

\section{Principal Results}

In this paper we report the formative evaluation of the use of the CHIEF system that integrates core algorithms reported previously [53], in addition to rules derived from existing HF guidelines, to generate a final CHI19 classification. The CHIEF processed $100 \%$ of the patients in the test set, with $92.1 \%$ of patients classified as meeting the CHI19 measure. Use of the CHIEF could potentially reduce or eliminate the need for routine human review of HF charts for the similar measures of CHF7 (HF-Outpatient LVF documented) and CHF14 (HF-Outpatient LVEF Less Than 40 on ACEI or ARB). CHF is a prevalent condition and CHIEF is an application that could provide an automated first review for HF patients to assess guideline-concordant care, and this data could potentially populate the existing EPRP dashboard automatically rather than through human review. During this process those patients who do not meet the measure could be identified; this would potentially allow a redeployment of human resources to evaluate why the care was not guideline-concordant and evaluate other quality of care issues. For example, more human resources could be used to assess patients who are at high risk for readmission, or who are frail and need additional care coordination.
The CHIEF also provides essential data that could be used in a dashboard to facilitate the identification of patients in a given provider's panel who may need additional medications such as an ACEI or ARB therapy or other medications, as guidelines are updated. Although the EPRP abstractors have access to the entire medical record for each patient they review, they focus only on finding the required data elements within the measure, rather than on a broad quality review in which other quality of care issues may be found. We obtained good results with the CHIEF using a limited document set. These findings suggest that the CHIEF is highly reliable and that its use could reduce or eliminate the expense associated with human review of $\mathrm{HF}$ patient records.

\section{Limitations}

There are several limitations to this work. First, it is likely that some clinical information was not documented in the patient charts and therefore could not be captured by the NLP system. However, we believe the impact of this missing information is minimal, given the importance and longstanding use of the HF quality measurement. Second, although the CHIEF performed well using VA text notes, it might not perform as well in non-VA settings. After training on new documents, we expect that it will perform similarly. Third, documents from only eight medical centers were used in this research; therefore, the CHIEF might under-perform initially when used with documents from other VA medical centers.

\section{Comparison with Prior Work}

This work builds on prior research in which we developed a system for concept extraction using a rule-based method. In the current CHIEF system, we used machine learning-based methods (sequential tagging) [40]. Our informatics work is also complementary to other uses of the NLP system in cases of patients identified as having HF or classified as having a preserved or reduced EF $[55,56]$, for the purposes of identifying patients for potential inclusion in research and those appropriate for treatment in primary care notes [57]. The relevance and importance of NLP tools in clinical practice are increasing. As such, testing and evaluating the implementation and deployment of NLP tools in clinical practice settings is an important next step.

Use of the CHIEF is also aligned with the current VA strategic plan for 2013-2018 that sets forth the principal that all initiatives be data-driven and evidence-based to help VA improve service delivery. The CHIEF has delivered promising results that could help achieve the goals of improving performance, advancing innovation, and increasing operational effectiveness and accountability in the VA, as well as in other health care organizations [58]. While CHIEF is not currently being implemented in the VA, we will seek potential implementation in VA and other settings.

Our work is important because some clinical information related to quality measures can only be found in text. Text data is not structured, so transformation of clinical text documents in a systematic, standardized process could result in its incorporation in a data warehouse across an enterprise, which would allow the use of the National Quality Forum information model 
designed for EHR-based quality measures, and facilitate the use of algorithms across institutions [59].

Due to the increasing availability of EHRs and the development of NLP techniques, many systems and techniques have been, and continue to be, developed to encode narrative data for a variety of uses such as: assessing the incidence rates of adverse events, evaluating the success of preventive interventions, benchmark performance across hospitals, determining cardiovascular risk factors, providing smoking cessation, providing real-time quality metrics for colonoscopies (in terms of identification of adenomas and sessile serrated adenomas), developing retrospective clinical data for use in cardiovascular research using NLP, and identifying ventilator-associated events (VAEs) and quality reporting and research in VAEs [60-62].

The Institute of Medicine envisioned a health care delivery system that would improve the quality of care and reduce costs. To accomplish this goal, it is important to create effective CDS delivered to clinicians through EHRs at the point of care [63]. The data captured from text, once transformed to structured data in the enterprise CDW, could be used in CDS.

Our methods complement other systems that identify hospitalized patients with HF in which machine learning approaches are used. Importantly, the complexity of implementation of these systems is well known and supports the assessment of barriers and facilitators for potential implementation [62,64]. The use of EHRs to automate publicly reported quality measures is receiving increasing attention, and is one of the promises of EHR implementation. Kaiser Permanente has fully or partly automated 6 of 13 the joint commission measure sets, resulting in an automated surgical site infection reporting process which reduced Kaiser Permanente's manual effort by $80 \%$, resulting is savings of US
\$2 million [65]. The VA could potentially realize reduced expenses associated with increased automation and decreased manual review of medical records for HF quality measurement.

The use of NLP for quality measures also adds to the capture of large amounts of clinical data from EHRs. The next step is to transform health care big data into actionable knowledge for quality improvement and research that helps to improve patient care, and potentially limit health care costs, with the aim of developing infrastructure with real-time data to support decision making [62-64,66,67]. The products of this NLP pipeline could potentially impact a number of clinical areas, including personalized CDS (eg, the suggestion to administer ACEIs/ARBs when inappropriately not administered), and could both facilitate appropriate care by promoting CDS use and prevent provider fatigue by reducing the incidence of false-positive notifications [53]. Our work is also in alignment with the recent description of the use of big data analytics in the VA, because the extracted data from our system has been scientifically evaluated for accuracy and reliability, and builds on the significant data resources in the CDW [33].

\section{Conclusions}

The CHIEF system accurately classified patients for the CHI19 performance measure, with high SN and PPV. HF is an increasingly prevalent condition among patients within the VA. Our results demonstrate that automated methods using NLP can improve the efficiency and accuracy of data collection and facilitate more complete and timely data capture at the time of discharge, at a potentially reduced cost. These tools also have applications in clinical care delivery and are aligned with US national strategic initiatives to use EHR data for quality improvement.

\section{Acknowledgments}

We thank the Office of Performance Measurement and the VA interviewees for assisting us in this research. JHG is a research health scientist at the VA Salt Lake City Health Care System. The views expressed in this article are those of the authors and do not necessarily reflect the position or policy of the Department of Veterans Affairs, the United States Government, or the academic affiliate organizations. This work was supported by the Department of Veterans Affairs, Veterans Health Administration, Office of Research and Development, IDEAS 2.0 Center, Health Services Research and Development project \#IBE 09-069, and by HIR 08-374 (Consortium for Healthcare Informatics Research). MEM was also supported in part by VA HSR\&D CDA 08-020.

\section{Conflicts of Interest}

None declared.

\section{Multimedia Appendix 1}

Three sets of rules to classify the patient.

\section{[PDF File (Adobe PDF File), 22KB-Multimedia Appendix 1]}

\section{References}

1. Benjamin E, Blaha M, Chiuve S, Cushman M, Das S, Deo R, American Heart Association Statistics CommitteeStroke Statistics Subcommittee. Heart disease and stroke statistics-2017 update: a report from the American Heart Association. Circulation 2017 Mar 07;135(10):e146-e603 [FREE Full text] [doi: 10.1161/CIR.0000000000000485] [Medline: 28122885]

2. VA Office of Research and Development, Health Services Research and Development Service. Quality Enhancement Research Initiative (QUERI) Chronic Heart Failure Fact Sheet. Palo Alto, California; 2014. URL: http://www. queri.research.va.gov/about/factsheets/chf factsheet.pdf [accessed 2017-09-27] [WebCite Cache ID 6tn9Tcdo8] 
3. Heidenreich P, Albert N, Allen L, Bluemke D, Butler J, Fonarow G, American Heart Association Advocacy Coordinating Committee, Council on Arteriosclerosis, Thrombosis and Vascular Biology, Council on Cardiovascular Radiology and Intervention, Council on Clinical Cardiology, Council on Epidemiology and Prevention, Stroke Council. Forecasting the impact of heart failure in the United States: a policy statement from the American Heart Association. Circ Heart Fail 2013 May;6(3):606-619 [FREE Full text] [doi: 10.1161/HHF.0b013e318291329a] [Medline: 23616602]

4. Centers for Disease Control and Prevention. Heart Failure Fact Sheet. 2017. URL: http://www.cdc.gov/dhdsp/data statistics/ fact_sheets/fs_heart_failure.htm [accessed 2017-09-27] [WebCite Cache ID 6tn9Eolnz]

5. American Heart Association. 2017. Heart disease and stroke statistics 2017 at-a-glance URL: https://www.heart.org/idc/ groups/ahamah-public/@wcm/@sop/@smd/documents/downloadable/ucm 491265.pdf [accessed 2017-09-27] [WebCite Cache ID 6tn9bbJXe]

6. Yancy CW, Jessup M, Bozkurt B, Butler J, Casey DE, Colvin MM, et al. 2017 ACC/AHA/HFSA focused update of the 2013 ACCF/AHA guideline for the management of heart failure: a report of the American College of Cardiology/American Heart Association Task Force on clinical practice guidelines and the Heart Failure Society of America. J Am Coll Cardiol 2017 Aug 08;70(6):776-803. [doi: 10.1016/j.jacc.2017.04.025] [Medline: 28461007]

7. Blecker S, Paul M, Taksler G, Ogedegbe G, Katz S. Heart failure-associated hospitalizations in the United States. J Am Coll Cardiol 2013 Mar 26;61(12):1259-1267 [FREE Full text] [doi: 10.1016/j.jacc.2012.12.038] [Medline: 23500328]

8. Ponikowski P, Anker SD, AlHabib KF, Cowie MR, Force TL, Hu S, et al. Heart failure: preventing disease and death worldwide. ESC Heart Fail 2014 Sep;1(1):4-25. [doi: 10.1002/ehf2.12005] [Medline: 28834669]

9. Agency for Healthcare Research and Quality. HCUP Fast Stats - Most Common Diagnoses for Inpatient Stays. Rockville, MD; 2017. URL: https://www.hcup-us.ahrq.gov/faststats/NationalDiagnosesServlet [accessed 2017-09-05] [WebCite Cache ID 6vZ4Bxe2L]

10. Polanczyk C, Newton C, Dec G, Di Salvo T. Quality of care and hospital readmission in congestive heart failure: an explicit review process. J Card Fail Dec 2001;7(4):a.

11. Pierre-Louis B, Rodriques S, Gorospe V, Guddati AK, Aronow WS, Ahn C, et al. Clinical factors associated with early readmission among acutely decompensated heart failure patients. Arch Med Sci 2016 Jun 01;12(3):538-545 [FREE Full text] [doi: 10.5114/aoms.2016.59927] [Medline: 27279845]

12. Komajda M, Lapuerta P, Hermans N, Gonzalez-Juanatey JR, van Veldhuisen DJ, Erdmann E, et al. Adherence to guidelines is a predictor of outcome in chronic heart failure: the MAHLER survey. Eur Heart J 2005 Aug;26(16):1653-1659. [doi: 10.1093/eurheartj/ehi251] [Medline: 15827061]

13. Luthi JC, Lund MJ, Sampietro-Colom L, Kleinbaum DG, Ballard DJ, McClellan WM. Readmissions and the quality of care in patients hospitalized with heart failure. Int J Qual Health Care 2003 Oct;15(5):413-421. [Medline: 14527985]

14. Basoor A, Doshi NC, Cotant JF, Saleh T, Todorov M, Choksi N, et al. Decreased readmissions and improved quality of care with the use of an inexpensive checklist in heart failure. Congest Heart Fail 2013;19(4):200-206 [FREE Full text] [doi: 10.1111/chf.12031] [Medline: 23910702]

15. Jha AK, Perlin JB, Kizer KW, Dudley RA. Effect of the transformation of the Veterans Affairs Health Care System on the quality of care. N Engl J Med 2003 May 29;348(22):2218-2227. [doi: 10.1056/NEJMsa021899] [Medline: 12773650]

16. Kupersmith J, Francis J, Kerr E, Krein S, Pogach L, Kolodner R, et al. Advancing evidence-based care for diabetes: lessons from the Veterans Health Administration. Health Aff (Millwood) 2007 Apr;26(2):156-168.

17. Blecker S, Agarwal SK, Chang PP, Rosamond WD, Casey DE, Kucharska-Newton A, et al. Quality of care for heart failure patients hospitalized for any cause. J Am Coll Cardiol 2014 Jan 21;63(2):123-130 [FREE Full text] [doi:

10.1016/j.jacc.2013.08.1628] [Medline: 24076281]

18. Centers for Medicare and Medicaid Services. 2017. Hospital Compare URL: https://www.cms.gov/medicare/ quality-initiatives-patient-assessment-instruments/hospitalqualityinits/hospitalcompare.html [accessed 2017-09-27] [WebCite Cache ID 6tn9pwtx1]

19. Payne VL, Hysong SJ. Model depicting aspects of audit and feedback that impact physicians' acceptance of clinical performance feedback. BMC Health Serv Res 2016 Jul 13;16:260 [FREE Full text] [doi: 10.1186/s12913-016-1486-3] [Medline: 27412170]

20. HealthIT.gov. 2017. EHR incentives \& certification, meaningful use definition \& objectives URL: http://www.healthit.gov/ providers-professionals/meaningful-use-definition-objectives [accessed 2017-09-27] [WebCite Cache ID 6tn9xCdsO]

21. Goulet J, Erdos J, Kancir S, Levin F, Wright S, Daniels S, et al. Measuring performance directly using the veterans health administration electronic medical record: a comparison with external peer review. Med Care 2007 Jan;45(1):73-79 [FREE Full text] [doi: 10.1097/01.mlr.0000244510.09001.e5] [Medline: 17279023]

22. Gray K, Sockolow P. Conceptual models in health informatics research: a literature review and suggestions for development. JMIR Med Inform 2016;4(1):A. [Medline: 26912288]

23. Carbonell JG, Hayes PJ. Natural language understanding. In: Shapiro SC, editor. Encyclopedia of Artificial Intelligence. Indianapolis: Wiley; Jan 2007:73-79.

24. McGinn T. Putting meaning into meaningful use: a roadmap to successful integration of evidence at the point of care. JMIR Med Inform 2016 May 19;4(2):e16 [FREE Full text] [doi: 10.2196/medinform.4553] [Medline: 27199223] 
25. Goldstein MK. Using health information technology to improve hypertension management. Curr Hypertens Rep 2008 Jun;10(3):201-207. [Medline: 18765090$]$

26. Kawamoto K, Houlihan C, Balas E, Lobach D. Improving clinical practice using clinical decision support systems: a systematic review of trials to identify features critical to success. BMJ 2005 Apr 02;330(7494):765 [FREE Full text] [doi: 10.1136/bmj.38398.500764.8F] [Medline: 15767266$]$

27. Bright T, Wong A, Dhurjati R, Bristow E, Bastian L, Coeytaux R, et al. Effect of clinical decision-support systems: a systematic review. Ann Intern Med 2012 Jul 03;157(1):29-43. [doi: 10.7326/0003-4819-157-1-201207030-00450] [Medline: 22751758]

28. Syrowatka A, Krömker D, Meguerditchian A, Tamblyn R. Features of computer-based decision aids: systematic review, thematic synthesis, and meta-analyses. J Med Internet Res 2016 Jan 26;18(1):e20 [FREE Full text] [doi: 10.2196/jmir.4982] [Medline: 26813512]

29. Sirajuddin A, Osheroff J, Sittig D, Chuo J, Velasco F, Collins D. Implementation pearls from a new guidebook on improving medication use and outcomes with clinical decision support. Effective CDS is essential for addressing healthcare performance improvement imperatives. J Healthc Inf Manag 2009;23(4):38-45 [FREE Full text] [Medline: 19894486]

30. Khorasani R, Hentel K, Darer J, Langlotz C, Ip I, Manaker S, et al. Ten commandments for effective clinical decision support for imaging: enabling evidence-based practice to improve quality and reduce waste. AJR Am J Roentgenol 2014 Nov;203(5):945-951. [doi: 10.2214/AJR.14.13134] [Medline: 25341131]

31. Pharmacy Benefits Management Strategic Healthcare Group, Medical Advisory Panel. PBM-MAP clinical practice guideline for the pharmacologic management of chronic heart failure in primary care practice. Publication no. 00-0015. Washington, DC: Veterans Health Administration, Department of Veteran Affairs; 2007. URL: https://www.healthquality.va.gov/ guidelines/cd/chf/chf full text.pdf [accessed 2018-01-08] [WebCite Cache ID 6wKbc656r]

32. VA Informatics and Computing Infrastructure (VINCI). 2017. URL: https://www.hsrd.research.va.gov/for_researchers/ vinci/ [accessed 2017-09-27] [WebCite Cache ID 6tnA446rDVA]

33. VA Corporate Data Warehouse (CDW). 2017. URL: https://www.hsrd.research.va.gov/for researchers/vinci/cdw.cfm [accessed 2017-09-27] [WebCite Cache ID 6vZ4xsAyF]

34. Bhatia R, Tu J, Lee D, Austin P, Fang J, Haouzi A, et al. Outcome of heart failure with preserved ejection fraction in a population-based study. N Engl J Med 2006 Jul 20;355(3):260-269. [doi: 10.1056/NEJMoa051530] [Medline: 16855266]

35. Knowtator. 2009 Jul 17. URL: http://knowtator.sourceforge.net/ [accessed 2018-01-08] [WebCite Cache ID 6wJ1KfdS1]

36. Ogren PV. A Protégé plug-in for annotated corpus construction. In: Proceedings of the 2006 Conference of the North American Chapter of the Association for Computational Linguistics on Human Language Technology. Stroudsburg: Association for Computational Linguistics; 2006 Presented at: 2006 Conference of the North American Chapter of the Association for Computational Linguistics on Human Language Technology; June 4-9, 2006; New York p. 273-275 URL: https://dl.acm.org/citation.cfm?id=1225785\&picked=prox\&preflayout=tabs [doi: $10.3115 / 1225785.1225791]$

37. Ashton C, Kuykendall D, Johnson M, Wray NP. An empirical assessment of the validity of explicit and implicit process-of-care criteria for quality assessment. Med Care 1999 Aug;37(8):798-808. [Medline: 10448722]

38. Apache UIMA. 2017. URL: http://uima.apache.org [accessed 2017-09-27] [WebCite Cache ID 6tnAFGnBQ]

39. Ferrucci D, Lally A. UIMA: an architectural approach to unstructured information processing in the corporate research environment. Nat Lang Eng 1999;10(3-4):327-348. [doi: 10.1017/S1351324904003523]

40. Garvin J, DuVall SL, South B, Bray B, Bolton D, Heavirland J, et al. Automated extraction of ejection fraction for quality measurement using regular expressions in Unstructured Information Management Architecture (UIMA) for heart failure. J Am Med Inform Assoc 2012;19(5):859-866 [FREE Full text] [doi: 10.1136/amiajnl-2011-000535] [Medline: 22437073]

41. South B, Shen S, Leng J, Forbush T, DuVall S, Chapman W. A prototype tool set to support machine-assisted annotation. In: BioNLP: Proceedings of the 2012 Workshop on Biomedical Natural Language Processing. Montreal: Association for Computational Linguistics; 2012 Jun 01 Presented at: Proceedings of the Workshop on Biomedical Natural Language Processing (BioNLP) 139; 2012; Montreal, QC p. 130-139.

42. Meystre S, Kim Y, Garvin J. Comparing methods for left ventricular ejection fraction clinical information extraction. In: Proceedings of the AMIA Summit on Clinical Research Informatics. Bethesda: American Medical Informatics Association; 2012 Mar 21 Presented at: Proceedings of the AMIA Summit on Clinical Research Informatics; 2012; San Francisco URL: https://knowledge.amia.org/amia-55142-cri2012a-1.644955?qr=1

43. Kim Y, Garvin J, Heavirland J, Meystre S. Improving heart failure information extraction by domain adaptation. Stud Health Technol Inform 2013;192:185-189. [Medline: 23920541]

44. Kim Y, Garvin J, Heavirland J, Meystre S. Medication prescription status classification in clinical narrative documents. In: AMIA Annual Symposium Proceedings. Bethesda: American Medical Informatics Association; 2014 Nov 15 Presented at: AMIA Annual Symposium 2014; 2014; Washington, DC URL: https://knowledge.amia.org/56638-amia-1.1540970?qr=1

45. Gobbel G, Reeves R, Jayaramaraja S, Giuse D, Speroff T, Brown S, et al. Development and evaluation of RapTAT: a machine learning system for concept mapping of phrases from medical narratives. J Biomed Inform 2014 Apr;48:54-65 [FREE Full text] [doi: 10.1016/j.jbi.2013.11.008] [Medline: 24316051]

46. Rycroft-Malone J. The PARIHS framework--a framework for guiding the implementation of evidence-based practice. $\mathrm{J}$ Nurs Care Qual 2004;19(4):297-304. [Medline: 15535533] 
47. Kitson A, Rycroft-Malone J, Harvey G, McCormack B, Seers K, Titchen A. Evaluating the successful implementation of evidence into practice using the PARiHS framework: theoretical and practical challenges. Implement Sci 2008 Jan 07;3:1 [FREE Full text] [doi: 10.1186/1748-5908-3-1] [Medline: 18179688 ]

48. Sittig D, Singh H. A new sociotechnical model for studying health information technology in complex adaptive healthcare systems. Qual Saf Health Care 2010 Oct;19 Suppl 3:i68-i74 [FREE Full text] [doi: 10.1136/qshc.2010.042085] [Medline: 20959322]

49. Van Rijsbergen CJ. Information Retrieval, 2nd edition. London: Butterworths; Nov 1979:374-375.

50. Cohen J. A coefficient of agreement for nominal scales. Educ Psychol Meas 1960;20(1):37-46. [doi: 10.1177/001316446002000104]

51. Garvin J, Heavirland J, Weaver A. Determining section types to capture key clinical data for automation of quality measurement for inpatients with heart failure. In: Poster Session Proceeding American Medical Informatics Association Annual Symposium. Bethesda: American Medical Informatics Association; 2012 Presented at: The American Medical Informatics Association Annual Symposium; November 3, 2012; Washington, DC URL: https://knowledge.amia.org/ amia-55142-a2012a-1.636547?qr=1

52. Hripcsak G, Heitjan DF. Measuring agreement in medical informatics reliability studies. J Biomed Inform 2002 Apr;35(2):99-110. [Medline: 12474424]

53. Meystre SM, Kim Y, Gobbel GT, Matheny ME, Redd A, Bray BE, et al. Congestive heart failure information extraction framework for automated treatment performance measures assessment. J Am Med Inform Assoc 2017 Apr 01;24(e1):e40-e46. [doi: 10.1093/jamia/ocw097] [Medline: 27413122]

54. Landis J, Koch GG. The measurement of observer agreement for categorical data. Biometrics 1977 Mar;33(1):159-174. [Medline: $\underline{843571]}$

55. Liu H, Bielinski SJ, Sohn S, Murphy S, Wagholikar KB, Jonnalagadda SR, et al. An information extraction framework for cohort identification using electronic health records. In: AMIA Joint Summits Translational Science Proceedings. Bethesda: American Medical Informatics Association; 2013 Presented at: American Medical Informatics Association Joint Summits Translational Science; March 18th; San Francisco, CA p. 149-153 URL: https://knowledge.amia.org/amia-55142-tbi2013a-1. 649951?qr=1

56. Pakhomov S, Weston S, Jacobsen S, Chute C, Meverden R, Roger V. Electronic medical records for clinical research: application to the identification of heart failure. Am J Manag Care 2007 Jun;13(6 Part 1):281-288 [FREE Full text] [Medline: $\underline{17567225]}$

57. Byrd R, Steinhubl S, Sun J, Ebadollahi S, Stewart WF. Automatic identification of heart failure diagnostic criteria, using text analysis of clinical notes from electronic health records. Int J Med Inform 2014 Dec;83(12):983-992 [FREE Full text] [doi: 10.1016/j.ijmedinf.2012.12.005] [Medline: 23317809]

58. Department of Veterans Affairs, Veterans Health Administration. 2013-2018 strategic plan URL: https://www.va.gov/ health/docs/VHA_STRATEGIC_PLAN_FY2013-2018.pdf [accessed 2017-09-27] [WebCite Cache ID 6tnANCEkO]

59. Thompson WK, Rasmussen LV, Pacheco JA, Peissig PL, Denny JC, Kho AN, et al. An evaluation of the NQF Quality Data Model for representing Electronic Health Record driven phenotyping algorithms. In: AMIA Annual Symposium Proceedings. https://knowledge.amia.org/amia-55142-a2012a-1.636547?qr=1: American Medical Informatics Association; 2012 Presented at: AMIA Annual Symposium Proceedings 2012; Nov 3, 2012; Chicago, IL p. 911-920 URL: http:/ leuropepmc.org/abstract/MED/23304366

60. Rochefort CM, Buckeridge DL, Tanguay A, Biron A, D'Aragon F, Wang S, et al. Accuracy and generalizability of using automated methods for identifying adverse events from electronic health record data: a validation study protocol. BMC Health Serv Res 2017 Feb 16;17(1):147 [FREE Full text] [doi: 10.1186/s12913-017-2069-7] [Medline: 28209197]

61. Khalifa A, Meystre S. Adapting existing natural language processing resources for cardiovascular risk factors identification in clinical notes. J Biomed Inform 2015 Dec;58 Suppl:S128-S132 [FREE Full text] [doi: 10.1016/j.jbi.2015.08.002] [Medline: 26318122]

62. Lan H, Thongprayoon C, Ahmed A, Herasevich V, Sampathkumar P, Gajic O, et al. Automating quality metrics in the era of electronic medical records: digital signatures for ventilator bundle compliance. Biomed Res Int 2015;2015:396508 [FREE Full text] [doi: 10.1155/2015/396508] [Medline: 26167484]

63. Jones JB, Stewart WF, Darer JD, Sittig DF. Beyond the threshold: real-time use of evidence in practice. BMC Med Inform Decis Mak 2013 Apr 15;13:47 [FREE Full text] [doi: 10.1186/1472-6947-13-47] [Medline: 23587225]

64. Blecker S, Katz SD, Horwitz LI, Kuperman G, Park H, Gold A, et al. Comparison of approaches for heart failure case identification from electronic health record data. JAMA Cardiol 2016 Dec 01;1(9):1014-1020 [FREE Full text] [doi: 10.1001/jamacardio.2016.3236] [Medline: 27706470]

65. Raju GS, Lum PJ, Slack RS, Thirumurthi S, Lynch PM, Miller E, et al. Natural language processing as an alternative to manual reporting of colonoscopy quality metrics. Gastrointest Endosc 2015 Sep;82(3):512-519 [FREE Full text] [doi: 10.1016/j.gie.2015.01.049] [Medline: 25910665]

66. Patterson OV, Freiberg MS, Skanderson M, Brandt CA, DuVall SL. Unlocking echocardiogram measurements for heart disease research through natural language processing. BMC Cardiovasc Disord 2017 Jun 12;17(1):151 [FREE Full text] [doi: 10.1186/s12872-017-0580-8] [Medline: 28606104] 
67. Ross MK, Wei W, Ohno-Machado L. "Big data” and the electronic health record. Yearb Med Inform 2014 Aug 15;9:97-104 [FREE Full text] [doi: 10.15265/IY-2014-0003] [Medline: 25123728]

\section{Abbreviations}

ACEI: angiotensin-converting enzyme inhibitor

ARB: angiotensin-receptor blocker

CHF7: HF-Congestive Heart Failure Outpatient Measure 7

CHF14: Congestive Heart Failure Outpatient Measure 14

CHI10: Congestive Heart Failure Inpatient Measure 10

CHI19: Congestive Heart Failure Inpatient Measure 19

CHI20: Congestive Heart Failure Inpatient Measure 20

CDS: clinical decision support

CHIEF: Congestive Heart Failure Information Extraction Framework

CDW: Corporate Data Warehouse

EF: ejection fraction

EHR: electronic health record

EPRP: External Peer Review Program

HF: heart failure

IAA: interannotator agreement

ICD-9-CM: International Classification of Diseases, 9th Revision, Clinical Modification

LVEF: left ventricular ejection fraction

LVF: left ventricular failure

NLP: natural language processing

PBM: Pharmacy Benefit Management

PPV: positive predictive value

PARiHS: Promoting Action on Research Implementation in Health Sciences

RNM: reasons no medications

RS: Reference Standard

SN: sensitivity

SP: specificity

SME: subject matter expert

TIU: text integration utilities

UIMA: Unstructured Information Management Architecture

VA: United States Department of Veterans Affairs

VAE: ventilator-associated event

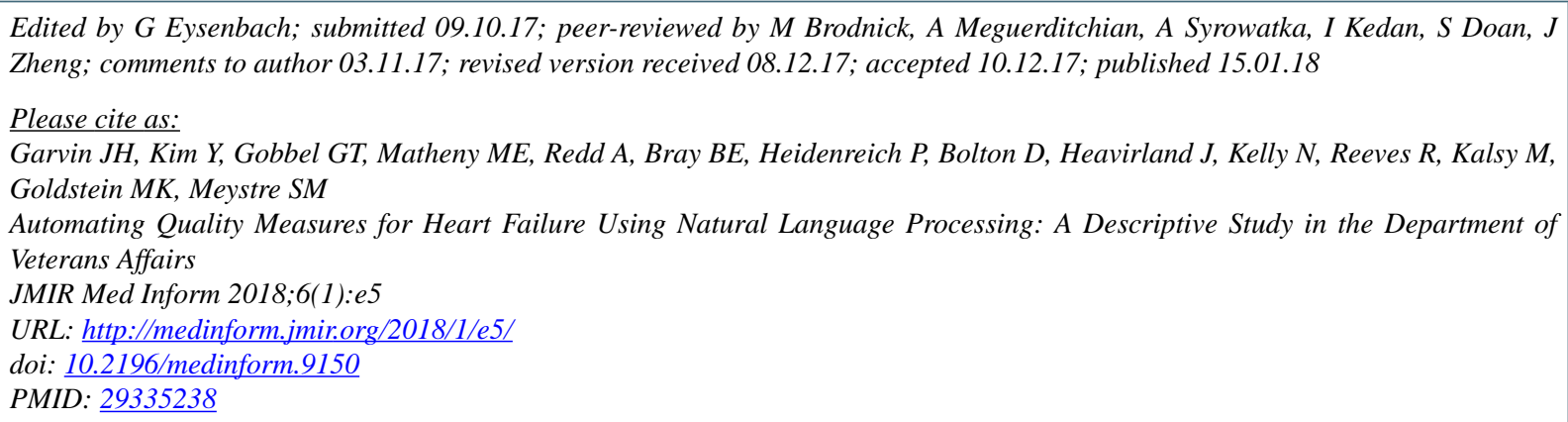

(CJennifer Hornung Garvin, Youngjun Kim, Glenn Temple Gobbel, Michael E Matheny, Andrew Redd, Bruce E Bray, Paul Heidenreich, Dan Bolton, Julia Heavirland, Natalie Kelly, Ruth Reeves, Megha Kalsy, Mary Kane Goldstein, Stephane M Meystre. Originally published in JMIR Medical Informatics (http://medinform.jmir.org), 15.01.2018. This is an open-access article distributed under the terms of the Creative Commons Attribution License (https://creativecommons.org/licenses/by/4.0/), which permits unrestricted use, distribution, and reproduction in any medium, provided the original work, first published in JMIR Medical Informatics, is properly cited. The complete bibliographic information, a link to the original publication on http://medinform.jmir.org/, as well as this copyright and license information must be included. 